\title{
Modelling Human-Computer Interactions based on Cognitive Styles within Collective Decision-Making
}

\author{
Nina Bakanova ${ }^{1}$, Arsenii Bakanov², Tatiana Atanasova ${ }^{3, *}$ \\ ${ }^{1}$ Keldysh Institute of Applied Mathematics - RAS, 125047, Russia \\ ${ }^{2}$ Institute of Psychology of Russian Academy of Sciences, 129366, Russia \\ ${ }^{3}$ Modelling and Optimization Department, Institute of Information and Communication Technologies - BAS, 1113, Bulgaria
}

\begin{tabular}{l} 
A R T I C L E I N F O \\
\hline Article history: \\
Received: 01 September, 2020 \\
Accepted: 13 January, 2021 \\
Online: 05 February, 2021 \\
\hline Keywords: \\
Human-computer communication \\
Information flows \\
Cognitive styles \\
Collective decision-making \\
\hline
\end{tabular}

A B S T R A C T
The article proposes an approach to evaluate human-computer interaction in the collective
decision-making model. It is believed that all team members interact with each other
through a distributed information system. The approach involves considering, when
modelling, the personality characteristics of perception, each member of the team as a set
of cognitive styles. Within the scope of the proposed technique, it is believed that
information flows are interconnected with the processes of collective decision-making,
which makes it possible to model the process of collective decision-making, monitor and
analyse the effectiveness of the collective's activities. Experimental studies accomplished
with statistical data processing were carried out and discussed.

\section{Introduction}

This paper is an extension of the work originally presented in Big Data, Knowledge and Control Systems Engineering (BdKCSE'2019) Conference [1]. The article further develops aspects of human-machine interaction in a distributed information environment. Here the emphasis is on collective decision-making taking into account the cognitive features of perception of team members.

The relevance of research in this area is due to a number of reasons, including the processes of globalization of the economic development of industrial sectors, the creation of a great number of large-scale, distributed corporations, concerns, holdings, and, accordingly, the decentralization of management processes controlled by parent organizations. Information interaction of such corporations is carried out through distributed information systems. The distributed information landscape is a genuine development of computerized, data and interaction technologies. The challenge of human communication with the distributed information ecosystem is gaining growing methodical and pragmatic importance.

A significant problem in the management of large-scale, distributed organizations are collective decision-making processes, which require the interaction of many people; this

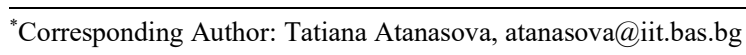

inevitably leads to the complication and delay of the decisionmaking process, as well as to the possible emergence of contradictions in the process of solving the problem.

The importance of taking into account the opinion of each member of the team, the importance of obtaining a coordinated, balanced solution to complex problems, the importance of ensuring transparency of the decision-making process in the team - all of the above emphasizes the relevance of developments in the field of creating automated tools to support collective decisionmaking. The development of mechanisms and techniques that provide modelling and visualization of collective decision-making processes will increase the efficiency and effectiveness of decision-making in a geographically distributed team through the implementation of modes of human-computer interaction.

When studying the processes of interaction in large-scale distributed information networks, we can talk about information flows connecting all users of the information system. As a result of the advance of information and computer technologies, now there are opportunities for the development of intelligent modules that allow to analyse, visualize and improve the efficiency of interaction processes in a team, including such as collective decision-making processes.

This article is devoted to the development of methods for modelling and presenting processes related to collective decision 
making. First, the development of decision theory over time is discussed. It is then proposed to use a cognitive modelling methodology to rank team members in the collective decisionmaking process. The reflection of the cognitive styles of the participants in the human-computer interaction with distributed information system is emphasized in further consideration. Experimental studies accomplished with statistical data processing were carried out. The cognitive styles of the collective members were investigated through an experimental study to be included in the cognitive map modelling. Finally, the results of the experiments are discussed.

\section{The Basis of Decision Theory}

The fundamental basis of decision theory in mathematics, computer science and economics is the provision of rational human behaviour and the theory of utility.

The game theory was introduced in 1944 by John von Neumann and Oskar Morgenstern in their book, entitled "Game Theory and Economic Behavior". However, in a number of researches works, for example in [2], it is shown that human behaviour is not always rational, and often, on the contrary, is irrational (from the point of view of gaining a win). As an example, to demonstrate the features of human behaviour, we can cite the paradox proposed by [3]. As a result of presenting lotteries to various groups of people, it was shown that people prefer the lottery where the risk of losing is excluded or minimal. Whereas the computer calculates probabilities and acts rationally, i.e., maximizes utility (or gain).

A study of the evolutionary development of work in the expansion of decision support systems as a scientific direction shows that from the moment Atanasoff and Berry began to develop the first digital computing device in 1939 (at Iowa State College) and before the 1980 s, the main goal was "to teach the computer to think like a person". Since the early 1980s up to the present time, the central paradigm has been the concept of "artificial intelligence" [4-10]. According to artificial intelligence professionals, the effectiveness of intelligent systems is determined both by formal mathematical schemes based on mathematical logic and by the knowledge of experts in a specific subject area, which can be explicated in the process of knowledge extraction. The analysis of scientific works in the field of knowledge extraction shows that, despite the significant success achieved in the advancement of intelligent, information systems, the key problem of creating any intelligent system is the process of extracting expert knowledge, as well as original heuristics used by specific experts to solve problems [11-15].

To date, technologies and methodologies for the design of knowledge-based intelligent systems have been developed, in which the sequential passage of the stages of acquiring expert knowledge is realized:

- the stages of extracting [16] and

- conceptual analysis of expert knowledge [17-21].

However, the actual problem of modelling and visualizing the collective decision-making process, as well as modelling and visualizing the information interaction between experts, has not received sufficient consideration, partly because this problem is interdisciplinary, as it is at the intersection of information technology, mathematics, sociology and psychology.

\section{Cognitive Maps for Modelling}

The use of models to study an object, phenomenon or process is a well-established and well-proven research method. By the term model, in this article, we mean a formal representation of an object, (process, phenomenon) in some form, intended for the study of this object. Formal representation of an object (process, phenomenon) can be:

- mathematical,

- simulation,

- sign-symbolic.

In the present study, cognitive maps were used as a basis for the model of making decision in information interaction within a distributed information system. Using of models based on cognitive maps made it possible to visualize information processes of remote (distributed) interaction in a team, including the processes of creating groups, monitoring remote activities of team members, etc. For visualization and ranking of team members, it is proposed to use the methodology of cognitive modelling [11, 2227]. According to the methodology, it is supposed to build a fuzzy model, visualized as a fuzzy graph (cognitive map), in which the vertices are team members, and the weighted arcs are information flows, relationships and social significance (weight, authority, awareness, experience, etc.) of each member of the team, the weight of each arc of the graph reflects the strength of the influence of a particular individual on the process of making a collective decision.

Information flows between team members, in general, can be verbal and non-verbal, mediated by the electronic information environment and not mediated. In this work, only flows mediated by a distributed information system are investigated. The considered information flows are subdivided into explicit and implicit, stable and unstable, as well as formal and informal.

Formally, a cognitive map can be symbolized as a directed sign graph $(F, W)$, where $F$ is the set of vertices - team members, $W=\left|w_{i j}\right|$ - adjacency matrix. The dynamics of the decision-making process is presented as a sequential set of situations $X(t-1), X(t)$, $X(t+1), \ldots, X(t+n)$, which are the situation state vectors at successive discrete times: $t-1, t, t+1, \ldots, t+n$, where $t$ is some number of such moment in time.

The interactions can be determined by summing all of them, according to the formula (1):

$$
X_{i}(t+1)=X_{i}(t)+\sum_{i=1}^{n}\left(X_{i-1}(t+1)-X_{i-1}(t)\right) W_{i, i-1}
$$

The use of cognitive maps allows modelling and visualizing not only the information flows, but also the configuration of the team in the process of collective decision taking, that is, the use of cognitive maps allows displaying the dynamic processes occurring in the team in the process of deciding.

\section{Cognitive Styles of the Collective Members in the Model}

The need for specific information (information flow) for each team member is determined by several factors influencing the 
request for information of a team member, namely: knowledge, skills, job responsibilities, style of activity, and personality characteristics of perception. By personal characteristics of perception, we mean the set of cognitive styles inherent in each member of the group. At the same time, we make it a condition that we consider in the model only personal characteristics of perception, since a person's personality traits are not limited to a set of cognitive styles.

\subsection{Cognitive-Style Characteristics}

According to several scientists, individual ways of processing information are largely determined by cognitive styles [28, 29]. Cognitive styles actively participate in the process of choice and making decisions in work, manage the emotional and behavioural characteristics of human activity [30]. Scientific works show the essential part of the cognitive and stylistic aspects of the subject in the execution of actions that involve self-government and answerability in during process of making decisions, particularly in highly uncertain conditions. In parallel, the assignment of psychological patterns as form-creating (combining, central) elements in the process of choosing an appropriate option is highlighted [31]. Of the entire set of cognitive styles given in the work [32], we will consider only three cognitive styles, namely: the "field dependence/field independence" style, the "narrow/wide range of equivalence" style, the "impulsivity/reflectivity". Detailed justification and appropriateness of the choice of the above styles are given in the work [33].

\subsection{Identifying the Cognitive-Style Characteristics}

As follows, we briefly describe the cognitive styles studied and present the methods used for the research.

The style "field dependence/field independence" is traditionally considered as a way of an individual to solve perceptual problems, and the presence of "the ability to overcome a complex context" (according to G. Witkin). To diagnose cognitive-style features, G. Witkin's "Included Figures" technique was used (evaluation of field dependence - field independence, individual variant) [34].

The style "narrow/wide range of equivalence" reflects the predominant orientation of the individual to the features of similarity or differences of classified objects, their obvious or hidden features. To diagnose these cognitive-style features, the method "Free sorting of objects" by R. Gardner and V. Kolga was used.

The style "impulsivity/reflectivity" characterizes individual differences in the speed and correctness of decisions made in situations of uncertainty and the presence of many alternatives. To diagnose these cognitive-style features, the method "Comparison of similar drawings" by J. Kagan (assessment of impulsivity reflectivity as the cognitive pace of decision-making) was used [35].

The choice of these particular styles for research is due to the fact that the team members united in the work on the project must have a good idea of the general structure of the entire project, understand the specifics of the work and the distinct (individual) tasks of other team members within the framework of this project, and have a proportionate cognitive pace of decision-making, carry out synthesis and analysis of project tasks.

www.astesj.com
In the framework of this study, the relationship between the cognitive-style characteristics of team members and the effectiveness of decision-making when working on a common project was studied.

\section{Experimental results}

To examine the cognitive-style characteristics of team members in the model, an experimental study was conducted. The most important phases of human interaction with the information system were modelled as the subject was needed to:

- familiarize s/himself with the content of the texts specially developed for this study,

- analyse the content of the texts,

- classify the content of the texts,

- then answer the proposed questions.

Also, during the study, the above mentioned cognitive-style characteristics were identified.

For this experiment, several texts from 2 to 8 pages in volume (250 - 300 words per one page) were prepared specifically. Throughout the experiment, the subject of investigation has to read these specifically arranged texts. After reading, the subject of the investigation was asked to answer questions about the structure of the text and to give a quantitative calculation of the discovered options. The volume of the presented material was taken into account to model the interaction with the information system. Gaze movements were recorded using specialized SMI equipment (http://www.smivision.com), which tracks the trajectory of the subject's gaze.

Several quantitative criteria for assessing the activity of information interaction have been established [1]. Statistical methods for data processing were applied together with using Student's t-test and Mann-Whitney U-test. Spearman's correlation coefficient was used to assess the relationship between variables. Student's t-test was used to analyse two independent data samples to compare the mean of the two populations. Mann-Whitney Utest determines whether the area of overlapping values between the two series is small enough.

The research results are shown in the Table. Questions of type 1 were used for the quantitative assessment, and questions of type 2 were questions about the structure of the text.

Note: Indicators for the assessment of the success and effectiveness of the activity are time for reading of the presented text (document); the keyword usage rate, i.e., how often the subject rereads the reference words; time for answering questions; coefficient of correct answer; coefficient of confidence in decision making i.e., how long the subject analyses the alternatives.

As an outcome of the analysis of the results obtained, the following interdependencies were revealed: 1) the more work experience, the less time during which the subjects look at the text of the document presented on the computer screen, and the less time spent on making a decision regarding the choice of an alternative, 2) on the contrary, the "coefficient of correctness of answers" is directly proportional to the indicator "work experience". That is, subjects with work experience more often solve problems correctly. 
Table 1: Correlation relationships between performance criteria and characteristics of socio-demographic status.

\begin{tabular}{|c|c|c|c|c|}
\hline Indicators & Gender & Age & Education & Experience \\
\hline \multicolumn{5}{|c|}{ Stage I. Reading text without pivot words } \\
\hline Reading time & 0,61 & 0,54 & 0,21 & $-0,72$ \\
\hline Answering time of quantitative questions & 0,17 & 0,27 & $-0,03$ & $-0,41$ \\
\hline Correctness of answer to quantitative questions & $-0,04$ & $-0,41$ & 0,28 & 0,68 \\
\hline Decision confidence factor & 0,43 & $-0,05$ & $-0,01$ & 0,06 \\
\hline Answering time of questions about text structure & 0,35 & $-0,16$ & 0,31 & 0,10 \\
\hline Correctness of answer to questions about structure & $-0,41$ & 0,15 & $-0,07$ & $-0,37$ \\
\hline Coefficient of confidence of answer about text structure & 0,05 & 0,15 & $-0,37$ & $-0,22$ \\
\hline \multicolumn{5}{|c|}{ Stage II. Reading text with pivot words } \\
\hline Reading time & 0,26 & 0,37 & $-0,03$ & $-0,52$ \\
\hline Answering time of quantitative questions & 0,17 & 0,22 & 0,07 & $-0,52$ \\
\hline Correctness of answer to quantitative questions & $-0,61$ & $-0,44$ & $-0,41$ & 0,41 \\
\hline Decision confidence factor & 0,48 & 0,26 & 0,04 & $-0,46$ \\
\hline Answering time of questions about text structure & $-0,43$ & $-0,32$ & $-0,08$ & 0,72 \\
\hline Correctness of answer to questions about structure & $-0,10$ & 0,20 & 0,40 & 0,17 \\
\hline Coefficient of confidence of answer about text structure & 0,78 & 0,68 & 0,48 & $-0,68$ \\
\hline
\end{tabular}

It should also be noted that statistical data processing not only made it possible to reveal the relationship between the "coefficient of correctness of answers" and the availability of work experience - this fact is quite expected and natural, but it made it possible to use the cognitive characteristics of the user in developing the model, making them dependent on the style of decision-making in the process of collective activity, with the efficiency and effectiveness of collective decision-making.

\section{Conclusion}

This article proposes an approach to developing a model of collective decision-making, which makes it possible to consider the cognitive features of a user in the process of interacting with a distributed information system. In the course of the research, it was revealed that respondents characterized by the breadth of the equivalence range (i. e. "synthetics") were the most successful in dealing with the intended tasks on reading, analysing and classifying the proposed texts, as compared with the respondents, style features of which are more inherent in the area of "narrow range of equivalence" (i.e. "analytics"). The results obtained also indicate that such a property as "field independence" allows individuals to cope with tasks more successfully than "field dependent" research participants.

In the process of modelling, analysis and monitoring of information flows were carried out to support the processes of remote group interaction based on a distributed information system. Information flows are interconnected with collective decision-making processes, which allow monitoring and analysing the effectiveness of the team's activities. For this purpose, it is possible to use the method of extracting specialized data samples from information arrays [36], where based on the analysis of the relationship of information flows; two classes-functions of collective information interaction were isolated:

- function-tasks - an interconnected sequence of information flows due to a sequence of actions team members aimed at solving a specific problem, as a result of which they have their own aspects and specifics in each case;

- functions-operations - an interconnected sequence of information flows due to the sequence of actions of team members, which are formal, standard and universal operations in the process of information interaction and are not aimed at solving a specific problem [37].

Based on the monitoring and analysis of the developed model, systematization, ranking and quantitative assessment of information flows were conducted.

\section{Conflict of Interest}

The authors declare no conflict of interest.

\section{References}

[1] A. Bakanov, T. Atanasova, N. Bakanova, "Cognitive Approach to Modeling Human-Computer Interaction with a Distributed Intellectual Information Environment," in 2019 Big Data, Knowledge and Control Systems Engineering, BdKCSE 2019, 2019, doi:10.1109/BdKCSE48644.2019.9010597.

[2] A. Tversky, D. Kahneman, "Judgment under uncertainty: Heuristics and biases," Science, 1974, doi:10.1126/science.185.4157.1124.

[3] M. Allais, "Le Comportement de l'Homme Rationnel devant le Risque: 
Critique des Postulats et Axiomes de l'Ecole Americaine," Econometrica, 1953, doi:10.2307/1907921.

[4] O.I. Larichev, Current Methodological Problems of Systems Analysis and Its Application, 1984, doi:10.1016/b978-0-08-030830-2.50013-1.

[5] A.B. Petrovsky, "Multiple criteria decision making: Discordant preferences and problem description," Journal of Systems Science and Systems Engineering, 2007, doi:10.1007/s11518-007-5032-z.

[6] A.B. Petrovsky, "Multi-method technology for group multi-attribute choice," in RPC 2018 - Proceedings of the 3rd Russian-Pacific Conference on Computer Technology and Applications, 2018, doi:10.1109/RPC.2018.8482143.

[7] A.K. Goel, J. Davies, Artificial intelligence, Book, 2019, doi:10.1017/9781108770422.026.

[8] F. Hayes-Roth, "Knowledge Based Expert Systems," Computer, 1984, doi:10.1109/MC.1984.1658976.

[9] C. Fyfe, "Advanced Information and Knowledge Processing," General Systems, 2010.

[10] B.R. Gaines, "Modeling practical reasoning," International Journal of Intelligent Systems, 1993, doi:10.1002/int.4550080105.

[11] R. Axelrod, Structure of decision: The cognitive maps of political elites, 2015, doi: $10.2307 / 2616237$.

[12] J.H. Boose, "A survey of knowledge acquisition techniques and tools," Knowledge Acquisition, 1989, doi:10.1016/S1042-8143(89)80003-2.

[13] J.H. Boose, B.R. Gaines, "Knowledge Acquisition for Knowledge-Based Systems: Notes on the State-of-the-Art," Machine Learning, 1989, doi:10.1023/A:1022662924615.

[14] S.J. Grossman, O.D. Hart, "The Costs and Benefits of Ownership: A Theory of Vertical and Lateral Integration," Journal of Political Economy, 1986, doi:10.1086/261404

[15] R. Kaluri, C.H. Pradeep Reddy, "An enhanced framework for sign gesture recognition using hidden markov model and adaptive histogram technique," International Journal of Intelligent Engineering and Systems, 2017, doi:10.22266/ijies2017.0630.02.

[16] R. Kaluri, C.H.P. Reddy, "Optimized feature extraction for precise sign gesture recognition using Self-Improved Genetic Algorithm," International Journal of Engineering and Technology Innovation, 2018.

[17] G. Lbov, V. Berikov, "Construction of an event tree on the basis of expert knowledge and time series," in Lecture Notes in Computer Science (including subseries Lecture Notes in Artificial Intelligence and Lecture Notes in Bioinformatics), 2011, doi:10.1007/978-3-642-22140-8_21.

[18] V. Desnitsky, I. Kotenko, "Expert knowledge based design and verification of secure systems with embedded devices," in Lecture Notes in Computer Science, 2014, doi:10.1007/978-3-319-10975-6_15.

[19] T. Atanasova, "Integrated semantic-based processes in digital home," Informatyka Ekonomiczna, 2014, doi:10.15611/ie.2014.3.02.

[20] H. Suzuki, R. Hishiyama, "An analysis of expert knowledge transmission using machine translation services", in SoICT '16 - Proceedings of the Seventh Symposium on Information and Communication Technology, 2016, doi.org/10.1145/3011077.3011085

[21] V.N. Golovachyova, G.Z. Menlibekova, N.F. Abayeva, T.L. Ten, G.D. Kogaya, "Construction of expert knowledge monitoring and assessment system based on integral method of knowledge evaluation," International Journal of Environmental and Science Education, 2016, doi:10.12973/ijese.2016.705a.

[22] T. Temel, F. Karimov, "Information systems model for targeting policies: A graph-theoretic analysis of expert knowledge," Expert Systems with Applications, 2019, doi:10.1016/j.eswa.2018.11.014.

[23] B. Kosko, "Fuzzy knowledge combination," International Journal of Intelligent Systems, 1986, doi:10.1002/int.4550010405.

[24] L.A. Ginis, "The use of fuzzy cognitive maps for the analysis of structure of social and economic system for the purpose of its sustainable development," Mediterranean Journal of Social Sciences, 2015, doi:10.5901/mjss.2015.v6n3s5p113.

[25] J.P. Carvalho, "Rule based fuzzy cognitive maps in humanities, social sciences and economics," Studies in Fuzziness and Soft Computing, 2012, doi:10.1007/978-3-642-24672-2_16.

[26] M. León, C. Rodriguez, M.M. García, R. Bello, K. Vanhoof, "Fuzzy cognitive maps for modeling complex systems," in Lecture Notes in Computer Science (including subseries Lecture Notes in Artificial Intelligence and Lecture Notes in Bioinformatics), 2010, doi:10.1007/9783-642-16761-4 15.

[27] N. Abramova, Z. Avdeeva, S. Kovriga, D. Makarenko., Subject-formal Methods Based on Cognitive Maps and the Problem of Risk Due to the Human Factor, 2010, doi:10.5772/7118.

[28] N. Volkova, A. Gusev, "Cognitive styles: Controversial issues and research problems," National Psychological Journal, 2016 , doi:10.11621/npj.2016.0203.

[29] M. Kozhevnikov, C. Evans, S.M. Kosslyn, "Cognitive Style as Environmentally Sensitive Individual Differences in Cognition," Psychological Science in the Public Interest, 2014, doi:10.1177/1529100614525555

[30] J.W. Atkinson, Motivation for achievement, 2015, doi:10.4324/9781315720951

[31] A.R. Masalimova, M.N. Mikhaylovsky, A. V. Grinenko, M.E. Smirnova, L.B. Andryushchenko, M.A. Kochkina, I.G. Kochetkov, "The interrelation between cognitive styles and copying strategies among student youth," Eurasia Journal of Mathematics, Science and Technology Education, 2019, doi:10.29333/ejmste/103565.

[32] E.Y. Korjova, O. V. Rudykhina, "The possibilities of typological approach in the study of epistemological styles," Vestnik of Saint Petersburg University. Psychology, 2016, doi:10.21638/11701/spbu16.2016.302.

[33] A. Bakanov, M. Zelenova Cognitive Styles as Determinants of Success in Professional Activity, Социальная Психология и Общество, 2015, doi:10.17759/sps

[34] H.A. Witkin, D.R. Goodenough, "Cognitive styles: essence and origins. Field dependence and field independence.," Psychological Issues, 1981.

[35] J. Kagan, "Reflection-impulsivity: The generality and dynamics of conceptual tempo," Journal of Abnormal Psychology, 1966, doi: $10.1037 / \mathrm{h} 0022886$

[36] N.B. Bakanova, V.M. Vishnevskii, "Modeling document movement in corporate systems document circulation," Automation and Remote Control, 2008, doi:10.1134/S0005117908090142.

[37] N. B. Bakanova, T. V. Atanasova, "Method for Automated Analysis of Users' Requests to Service Centre of Information Networks in OIS," Problems of Engineering Cybernetics and Robotics, 2020, doi: 10.7546/PECR.74.20.04 